\title{
Suplementação Energético-Protéica no Desenvolvimento Corporal de Novilhas Jersey em Pastejo
}

\author{
Lília Maria da Rosa Pereira1, Vivian Fischer², Claiton Baes Moreno ${ }^{3}$, Everson Xavier Ferreira ${ }^{4}$, \\ René Mauricio Patiño Pardo ${ }^{1}$, Jorge Fainé Gomes ${ }^{5}$, Pedro Lima Monks ${ }^{6}$
}

\begin{abstract}
RESUMO - O experimento foi desenvolvido com a finalidade de avaliar os efeitos de três tipos de suplementação energética-protéica à base de milho moído e farelo de soja sobre o desenvolvimento corporal de fêmeas Jersey em pastejo. Foram utilizadas 15 novilhas (peso médio de 142,2 \pm 7,8 kg e 6 a 18 meses de idade), mantidas em pastejo rotativo, com lotação fixa, em uma pastagem cultivada com azevém anual (Lolium multiflorum, Lam.) e aveia preta (Avena strygosa, Schreb). Foram fornecidos milho moído e farelo de soja, na quantidade equivalente a $0,75 \%$ do peso vivo, nos tratamentos: $100 \%$ milho moído; $70 \%$ milho moído + 30\% farelo de soja; e $40 \%$ milho moído $+60 \%$ farelo de soja. Os animais foram divididos conforme o peso corporal inicial e distribuídos aleatoriamente aos tratamentos, segundo delineamento de blocos completos casualizados em parcelas subdivididas. As avaliações foram feitas durante seis períodos de 28 dias. Não foi observado efeito dos níveis de suplemento sobre ganho médio diário de peso (GMD), ganho total de peso, incrementos de altura e perímetro torácico, provavelmente em razão do nível de massa de forragem e da qualidade nutricional da pastagem utilizada.
\end{abstract}

Palavras-chave: altura, condição corporal, consumo, ganho de peso, pastejo, perímetro torácico

\section{Energy-Protein Supplementation on Body Development of Grazing Jersey Heifers}

ABSTRACT - The trial was conducted to evaluate the effects of three levels of energy-protein supplementation with corn ground and soybean meal on grazing dairy heifers body development. Fifteen Jersey heifers, aged of 6 to 18 months and weighing $142,2 \pm 7,8 \mathrm{~kg}$, were used. Animals were kept under rotational grazing system and fixed stocking rate on a ryegrass and black oats pasture. Animals were classified by their initial body weight and randomly assigned to treatments according to a complete randomized block in a split plot design: $100 \%$ corn ground, $70 \%$ corn ground $+30 \%$ soybean meal, $40 \%$ corn ground $+60 \%$ soybean meal. Evaluation was performed over six periods of 28 days. No effects for treatments were detected on animals body development attributes as increases in daily live weight gain, total live weight gain, increments of height at withers and heart girt, probably due to high values for pasture quality herbage mass.

Key Words: body condition score, grazing, height at withers, hearth girth, intake, weight gain

\section{Introdução}

No Rio Grande do Sul, as pastagens nativas e cultivadas ocupam cerca de 12 milhões de hectares, representando $53 \%$ da área total do estado, com um rebanho bovino de, aproximadamente, 14 milhões de cabeças, dos quais 1,5 milhões são animais jovens de 1 a 2 anos (IBGE, 1998).

A variação sazonal qualitativa e quantitativa das pastagens do Rio Grande do Sul é bastante conhecida (Jacques et al., 1995, 1999). A predominância de espécies estivais que diminuem drasticamente sua velocidade de crescimento abaixo de $15^{\circ} \mathrm{C}$ é uma das causas da redução da oferta de forragem durante o outono e o inverno, com redução da quantidade de nutrientes digestivos, o que provoca variações cíclicas de ganhos e perdas de peso ao longo do ano e afeta negativamente a produtividade animal e a rentabilidade destes sistemas (Bittencourt, 2000). Assim, para manter o equilíbrio entre o rendimento individual e a produção por hectare, dispõe-se de diferentes estratégias - uso de pastagens cultivadas; suplementação, que, em animais mantidos em regime de pastejo, visa maximizar o consumo e a digestibilidade da forragem disponível (Reis et al., 1996); entre outras.

\footnotetext{
${ }^{1}$ Aluno do Mestrado de Zootecnia - UFPEL - Caixa postal 354 - 96001- 970 - Pelotas - RS. Pesquisa financiada pelo PPGZ-UFPEL e EMBRAPA - CPACT (pereiralilia@hotmail.com).

2 Professor Adjunto do Departamento de Zootecnia, Faculdade de Agronomia - UFPEL - Pelotas - RS. Bolsista do CNPq (vfried@ufpel.tche.br).

${ }^{3}$ Aluno do curso de Medicina Veterinária. Bolsista Iniciação Científica FAPERGS.

${ }^{4}$ Aluno do curso de Medicina Veterinária. Bolsista Iniciação Científica CNPq.

5 Pesquisador da EMBRAPA, CPACT.

${ }^{6}$ Professor Adjunto do Departamento de Zootecnia, Faculdade de Agronomia - UFPEL - Pelotas - RS.
} 
Cresce o número de produtores que suplementam os animais em pastejo, em razão da boa relação de preço carne/grão e da facilidade de execução. O fornecimento de níveis moderados de energia a animais em pastejo é importante na redução do efeito de flutuações na oferta forrageira durante o ano, no entanto, devem-se considerar as possíveis interações negativas do amido sobre a digestibilidade da fibra, sobretudo quando fornecidos níveis de grão superiores a $1 \%$ do peso vivo (Horn et al., 1995). Os suplementos podem elevar a produção animal, graças à melhor utilização da pastagem, provendo nutrientes adicionais.

A suplementação de altas quantidades de energia digestível permite aumento das taxas de lotação e da produção por área (Moore, 1980; Boin \&Tedeschi, 1996; Rocha, 1999).

Objetivou-se, com este trabalho, avaliar o efeito de três tipos de suplementação energético-protéica sobre o desenvolvimento corporal de novilhas Jersey em pastejo, durante o ciclo de desenvolvimento da pastagem.

\section{Material e Métodos}

Este experimento foi desenvolvido na Estação Experimental Terras Baixas da Embrapa Clima Temperado, no município de Capão do Leão, RS, no período de 18 de maio a 03 de novembro de 2000. O município do Capão do Leão está situado na região sudeste do Rio Grande do Sul, a $31^{\circ}$ 52' 24 " de latitude sul e $52^{\circ} 21^{\prime} 24^{\prime \prime}$ de longitude oeste, em uma região de planície, a sete metros acima do nível do mar.

O município apresenta clima temperado, com chuvas bem distribuídas e verões amenos, onde a temperatura média anual é de $17,4^{\circ} \mathrm{C}$, com amplitude térmica anual de $10,6^{\circ} \mathrm{C}$ e umidade relativa média do ar de $80 \%$. O inverno caracteriza-se com valores normais para temperatura média $\left(13,5^{\circ} \mathrm{C}\right)$, temperatura mínima $\left(9,4^{\circ} \mathrm{C}\right)$, temperatura máxima $\left(18,3^{\circ} \mathrm{C}\right)$, precipitação pluviométrica $(125,1 \mathrm{~mm})$, umidade relativa do ar $(83,7 \%)$, número de dias de chuva $(10,5)$, número de dias de geada $(8,8)$ e insolação (153 horas).

A área total do experimento (5,3 ha) foi dividida por cerca eletrificada em seis piquetes. A temperatura média mensal durante o período experimental foi de $14,9^{\circ} \mathrm{C} \pm 4,5^{\circ} \mathrm{C}$, com precipitação pluviométrica mensal média de $168 \mathrm{~mm}$.

Foram utilizadas 15 novilhas puras de origem da raça Jersey, com idade inicial entre 6 e 18 meses, peso médio inicial de $84,2 \mathrm{~kg}$ a $225,6 \mathrm{~kg}$ e escore de condição corporal inicial entre 1 e 2,5 (Tabela 1). Os animais receberam medicação antiparasitária sete dias antes do início do experimento. As novilhas

Tabela 1 - Valores de condição corporal das novilhas ao início de cada período experimental (escore de 1 a 5, em que 1 = muito magro e 5 = muito gordo)

Table 1 - Values of body condition score for heifers at the beginning of each experimental period (scores from 1 to 5 , where $1=$ very thin and $5=$ very fat)

\begin{tabular}{cccccccc}
\hline & & \multicolumn{5}{c}{ Período (Period) $^{1}$} \\
\cline { 2 - 7 } $\begin{array}{c}\text { Animal } \\
\text { Animal }\end{array}$ & $\begin{array}{c}\text { Escore de condição corporal } \\
\text { Body condition score }\end{array}$ & 1 & 2 & 3 & 4 & 5 & 6 \\
\hline 98 & 2 & $2,5^{*}$ & 3 & 3 & 3,5 & 4 & 4 \\
100 & 2 & 2 & 2 & 2,5 & 3,5 & 4 & 4 \\
101 & 1,5 & 1,5 & 2 & 2,5 & 3,5 & 3,8 & 4 \\
102 & 1,6 & 1,8 & 2 & 2,5 & 3,5 & 4 & 4 \\
104 & 1,8 & 2 & 3 & 3 & 2,6 & 3 & 3 \\
105 & 1,3 & $1,3^{*}$ & 2 & 2 & 1,8 & 2 & 2 \\
106 & 1,8 & 2 & 2 & 2,5 & 2,6 & 3 & 3 \\
107 & 2 & $2 *$ & $1,6^{*}$ & 2 & 2,3 & 3,2 & 3 \\
109 & 2 & 2 & 1,7 & 2 & 2 & 3 & 3 \\
110 & 2 & 1,2 & 1,5 & 1,5 & 2,3 & 2,3 \\
11 & 1 & 1,5 & $1,3 *$ & 1,5 & 1,5 & 2 & 2 \\
113 & 1,5 & 1,5 & 1,5 & 2 & 1,6 & 2 & 2 \\
114 & 1,6 & 1,5 & $1,5^{*}$ & 1,5 & 1,5 & 2 & 2 \\
115 & 1,3 & 1 & 1,5 & 1,6 & 1,4 & 2 & 2 \\
\hline
\end{tabular}

* Diarréia intensa (intense diarea).

${ }^{* *}$ Animal com infecção respiratória (Animal with respiratory infection).

1 Cada período corresponde a 28 dias (Each period lasted for 28 days).

\section{R. Bras. Zootec., v.34, n.1, p.175-187, 2005}


foram avaliadas durante seis períodos experimentais de 28 dias.

O período 1 transcorreu de 18/05 a 14/06; o 2 , de $15 / 06$ a $15 / 07$; o 3 , de $16 / 07$ a $11 / 08$; o 4 , de 12/08 a 08/09; o 5, de 09/09 a 06/10; e o 6, de 07/10 a 03/11.

Os animais foram mantidos sob uma pastagem cultivada de azevém anual (Lolium multiflorum, Lam) e aveia preta (Avena strigosa, Schreb), semeados em cultivo mínimo, respectivamente a lanço e em linha, em 1 o de abril de 2000, quando foram utilizados $20 \mathrm{~kg}$ de sementes de azevém e $95 \mathrm{~kg}$ de sementes de aveia preta por hectare. A adubação foi feita com $100 \mathrm{~kg} \mathrm{da}$ formulação 5-20-20 por hectare. Inicialmente, a área experimental havia recebido $2 \mathrm{~kg}$ de dessecante glifosato e 1 litro de óleo mineral sobre pastagem cultivada com milheto, a qual após dessecada foi incorporada ao solo por intermédio de grade de disco.

A análise laboratorial do solo da área experimental apresentou as seguintes características: $15 \%$ de argila; pH 4,8; matéria orgânica 1,61\%; 48,8 ppm de fósforo; 121 ppm de potássio; 8 ppm de sódio; 0,5 meq/100 mL de alumínio; $2,1 \mathrm{meq} / 100 \mathrm{~mL}$ de cálcioe $0,6 \mathrm{meq} / 100 \mathrm{~mL}$ de magnésio. $\mathrm{O}$ pastejo foi conduzido segundo o sistema rotativo com lotação fixa e os animais foram manejados em conjunto durante todo o experimento.

Na Tabela 2, é apresentada os valores de composição química do milho moído e do farelo de soja utilizados na suplementação dos animais, considerados para calcular a contribuição de nutrientes do suplemento oferecido nos tratamentos experimentais.

Foram realizadas estimativas da massa de forragem presente na entrada e na saída dos animais em cada piquete, utilizando-se um disco graduado, com a leitura verificada em 50 pontos por piquete, e a técnica da dupla amostragem (leitura com o disco e corte de 10 amostras no nível do solo em cada

Tabela 2 - Composição química média do milho e da soja usados (\% da matéria seca)

Table 2 - Chemical composition of corn grain and soybean meal (\% dry matter)

\begin{tabular}{lcccc}
\hline & $\mathrm{MS}(\%)$ & $\mathrm{PB}(\%)$ & $\mathrm{FDN}(\%)$ & $\mathrm{FDA}(\%)$ \\
& $D M$ & $C P$ & $N D F$ & $A D F$ \\
\hline $\begin{array}{l}\text { Grão de milho } \\
\text { Corn grain }\end{array}$ & 90,74 & 9,32 & 31,69 & 2,70 \\
$\begin{array}{l}\text { Farelo de soja } \\
\text { Soybean meal }\end{array}$ & 92,74 & 52,63 & 33,00 & 9,31 \\
\hline
\end{tabular}

R. Bras. Zootec., v.34, n.1, p.175-187, 2005 piquete) (Gardner, 1986). A taxa de crescimento da forragem foi calculada subtraindo-se da quantidade de matéria seca presente por hectare, no início da utilização de um piquete, a quantidade de matéria seca no final da utilização do mesmo piquete no período anterior, dividido pelo número de dias de repouso do referido piquete (Gardner, 1986). O tempo de ocupação dos piquetes foi de 4 a 6 dias, enquanto o tempo de repouso (sem pastejo), de 22 a 24 dias, em cada período experimental.

Foi determinada a proporção de material vivo e de material morto da pastagem, a partir da colheita de amostras no início e metade de cada período de ocupação dos piquetes, durante todo o experimento. Quinze subamostras de cada piquete foram cortadas rente ao solo, com tesoura de esquilar, na área compreendida pelo interior de um aro metálico de $0,088 \mathrm{~m}^{2}$. As amostras foram colocadas no mesmo saco plástico, formando uma amostra composta. Os componentes foram separados com o material fresco no mesmo dia da coleta e, posteriormente, secos em estufa a $60^{\circ} \mathrm{C}$, durante 48 horas. Após, as amostras foram novamente pesadas e moídas em peneira com crivos de $1,0 \mathrm{~mm}$, para posterior análise química. Os resultados foram expressos como proporção dos componentes vivo/morto.

A colheita das amostras de pasto foi realizada segundo o método de simulação de pastejo, pelo corte manual, durante a atividade de pastejo, próxima aos locais onde os animais pastejavam, nos cinco dias consecutivos em que se realizou a observação do comportamento ingestivo em cada período experimental. Essas amostras foram secas em estufa a $60^{\circ} \mathrm{C}$, durante 48 horas, e, posteriormente, moídas em peneira com crivos de $1,0 \mathrm{~mm}$, para realização de análises químicas. Determinou-se a composição química da massa de forragem e da forragem colhida manualmente com simulação de pastejo, por intermédio das análises de matéria seca (MS), cinzas (CZ), matéria orgânica (MO), proteína bruta (PB), segundo AOAC (1975), e as porcentagens de fibra em detergente neutro (FDN) e fibra em detergente ácido (FDA), segundo a metodologia de Goering \& Van Soest (1970). A determinação da digestibilidade in vitro da matéria seca (DIVMS) e da matéria orgânica (DIVMO) para as amostras obtidas de simulação de pastejo seguiu a metodologia de Tilley \& Terry (1963).

Os três tipos de suplementação constaram de: 1) $100 \%$ de milho moído;2) $70 \%$ de milho moído + 30\% de farelo de soja; e 3) $40 \%$ de milho moído + $60 \%$ de 
farelo de soja. O suplemento foi fornecido na quantidade equivalente a $0,75 \%$ do peso vivo dos animais, calculado por ocasião das pesagens e fornecido diariamente às $14 \mathrm{~h}$, em cochos com divisórias, para permitir o consumo individualizado e controlado. O consumo diário do suplemento foi calculado como a diferença entre a quantidade de suplemento oferecido e as sobras recolhidas. Os animais tiveram livre acesso ao sal mineralizado e à água.

$\mathrm{Na}$ véspera das pesagens, realizadas ao início e ao final de cada período experimental, as novilhas foram pesadas às $8 \mathrm{~h}$ do dia seguinte, após 14 horas de jejum completo. Nestas oportunidades, foram realizadas medições de altura na cernelha, com bengala de Thomas, e de perímetro torácico, com fita métrica. Os animais foram distribuídos em cinco blocos compostos por três animais, conforme peso corporal inicial: no bloco 1 de 225,6 kg; no bloco 2 de $174 \mathrm{~kg}$; no bloco 3 de 127,6 kg; no bloco 4 de $94 \mathrm{~kg}$; e no bloco 5 de $84,2 \mathrm{~kg}$. Cada animal recebeu aleatoriamente um dos três tratamentos de suplementação energético-protéica, segundo delineamento em blocos completos casualizados em parcelas subdivididas. Os tipos de suplementação foram representados pelas parcelas e os períodos, pelas subparcelas.

Durante 12 dias, nos períodos experimentais III e VI, foi efetuada a administração de óxido de cromo $\left(\mathrm{Cr}_{2} \mathrm{O}_{3}\right)$ em pó, via oral, misturado ao suplemento destinado a cada animal, em dose diária de 8 gramas, fornecido em duas refeições, às $9 \mathrm{~h}$ e $14 \mathrm{~h}$. Nos últimos cinco dias de fornecimento de óxido de cromo aos animais, concomitante ao período de observação do comportamento ingestivo diurno das fêmeas, foram coletadas fezes do reto de cada animal, duas vezes ao dia, enquanto eles se encontravam dentro das baias de alimentação. Ao final do período experimental, as fezes foram secas em estufa a $60^{\circ} \mathrm{C}$ até atingir peso estável e, então, moídas em peneira com crivos de $1,0 \mathrm{~mm}$. Foram realizadas amostras compostas por animal e por período experimental para análise quantitativa da presença de cromo, por intermédio do método analítico descrito por Piaggio (1994), executada no Laboratório de Nutrição Animal, Centro de Ciências Rurais, UFSM. Foi calculada a produção fecal dividindo-se a concentração de cromo nas fezes pela quantidade fornecida. $\mathrm{O}$ consumo total de matéria seca (kg/animal/dia) foi calculado dividindose os dados de produção fecal pelo valor da indigestibilidade (1-DIVMO). O consumo de pasta- gem foi calculado como a diferença entre o consumo matéria seca total e o consumo de matéria seca do suplemento.

As variáveis relativas ao desenvolvimento corporal (ganho de peso, perímetro torácico, altura na cernelha, condição corporal) e ao consumo foram submetidas à análise da variância, considerando os efeitos de bloco, de período e de tratamento, usando o procedimento GLM do SAS (1989). O teste de separação de médias utilizado foi dms de Fisher (Lsmeans), com nível de significância de 0,05. O modelo estatístico adotado pode ser expresso como:

$$
\mathrm{Y}_{\mathrm{ijkl}}=\mu+\mathrm{B}_{\mathrm{i}}+\mathrm{S}_{\mathrm{j}}+\mathrm{BS}_{\mathrm{ij}}+\mathrm{P}_{\mathrm{k}}+\mathrm{SP}_{\mathrm{jk}}+\mathrm{E}_{\mathrm{ijkl}} \text {, }
$$

em que $Y_{i j k l}=$ observações realizadas com cada animal 1, no bloco i, com o suplemento j, no período k; $\mu=$ média geral do experimento; $\mathrm{B}_{0}=$ bloco $(\mathrm{GL}=4)$; $\mathrm{S}_{\mathrm{i}}=$ suplemento $(\mathrm{GL}=2) ; \mathrm{BS}_{\mathrm{ij}}=$ interação entre blocos e suplemento (erro tipo a); $\mathrm{P}_{\mathrm{k}}=$ período de avaliação $(\mathrm{GL}=5$, para consumo $\mathrm{GL}=1) ; \mathrm{SP}_{\mathrm{jk}}=$ interação entre suplemento e período $(\mathrm{GL}=10$, para consumo GL = 2); $\mathrm{E}_{\mathrm{ijkl}}=$ resíduo (erro tipo b).

\section{Resultados e Discussão}

Não houve efeito do tipo de suplementação fornecida sobre o desenvolvimento corporal das novilhas. Houve efeito significativo de período sobre ganho de peso, ganho de peso diário, ganho de altura e ganho de altura diário. Constam da Tabela 3 os valores das probabilidades de rejeição da hipótese de nulidade do efeito dos tipos de suplementação sobre o desempenho corporal das novilhas.

Os tipos da suplementação energético-protéica não influenciaram $(\mathrm{P}>0,05)$ as variáveis de desenvolvimento corporal dos animais (Tabela 4), em razão, provavelmente, do atendimento das exigências nutricionais dos animais exclusivamente pela pastagem, devido à sua massa de forragem e qualidade nutritiva, o que permitiu consumo elevado de matéria seca de pastagem (Tabela 5).

Este resultado está em concordância com Campos \& Lizieire (1998), que, ao trabalharem com animais da raça holandesa, mostraram a possibilidade de ganhos de $0,65-0,70 \mathrm{~kg} / \mathrm{dia}$, desde o desaleitamento (aos 55-65 dias de idade) até as novilhas atingirem peso ideal de cobertura, apenas com a utilização de volumosos de excelente qualidade, como o azevém anual, ad libitum.

\section{R. Bras. Zootec., v.34, n.1, p.175-187, 2005}


Tabela 3 - Valores das probabilidades de rejeição da hipótese de nulidade do efeito do tipo de suplementação energético-protéica sobre o desenvolvimento corporal das novilhas

Table 3 - Values of probabilities for rejection of null hypothesis of energy-protein supplementation type effect on heifers body development

\begin{tabular}{|c|c|c|c|c|c|}
\hline $\begin{array}{l}\text { Variáveis } \\
\text { Variables }\end{array}$ & $\begin{array}{l}\text { Tratamento } \\
\text { Treatment }\end{array}$ & $\begin{array}{l}\text { Bloco } \\
\text { Block }\end{array}$ & $\begin{array}{c}\text { Bloco } \mathrm{x} \text { Tratamento } \\
\text { Block } x \text { Treatment }\end{array}$ & $\begin{array}{l}\text { Período } \\
\text { Period }\end{array}$ & $\begin{array}{c}\text { Período } \mathrm{x} \text { Tratamento } \\
\text { Period } x \text { Treatment }\end{array}$ \\
\hline $\begin{array}{l}\text { Ganho de peso total } \\
\text { Total weight gain }\end{array}$ & 0,7702 & 0,1415 & 0,2535 & 0,0002 & 0,9943 \\
\hline $\begin{array}{l}\text { Ganho de peso médio } \\
\text { diário } \\
\text { Daily weight gain }\end{array}$ & 0,7605 & 0,1490 & 0,2700 & 0,0001 & 0,9935 \\
\hline $\begin{array}{l}\text { Ganho de perímetro } \\
\text { total }\end{array}$ & 0,1474 & 0,5687 & 0,9682 & 0,3371 & 0,7432 \\
\hline $\begin{array}{l}\text { Total heart girth gain } \\
\text { Ganho de perímetro } \\
\text { médio diário }\end{array}$ & 0,1430 & 0,4875 & 0,9626 & 0,3952 & 0,7267 \\
\hline $\begin{array}{l}\text { Daily heart girth gain } \\
\text { Ganho de altura total } \\
\text { Total height gain }\end{array}$ & 0,8332 & 0,9196 & 0,9999 & 0,0017 & 0,2746 \\
\hline $\begin{array}{l}\text { Ganho de altura } \\
\text { médio diário } \\
\text { Daily height gain }\end{array}$ & 0,1111 & 0,7366 & 0,9999 & 0,0021 & 0,6500 \\
\hline
\end{tabular}

Tabela 4 - Valores médios quanto ao ganho de peso vivo total e diário $(\mathrm{kg})$, ganho de altura total e diário (cm) e ganho de perímetro torácico total e diário $(\mathrm{cm})$ de acordo com o tipo de suplementação energético-protéica

Table 4 - Mean values for total and daily gain of body weight $(\mathrm{kg})$, total and daily height gain $(\mathrm{cm})$, total and daily hearth girth gain $(\mathrm{cm})$, according to the energy-protein supplementation type

\begin{tabular}{|c|c|c|c|c|c|}
\hline \multirow{3}{*}{$\begin{array}{l}\text { Item } \\
\text { Item }\end{array}$} & \multirow{2}{*}{\multicolumn{3}{|c|}{$\begin{array}{c}\text { Suplemento } \\
\text { Supplement }\end{array}$}} & \multirow{3}{*}{$\begin{array}{l}\text { Média } \\
\text { Mean }\end{array}$} & \multirow{3}{*}{$\begin{array}{c}\mathrm{DP}^{1} \\
S D\end{array}$} \\
\hline & & & & & \\
\hline & $\begin{array}{c}100 \% \mathrm{~m}^{2} \\
100 \% c\end{array}$ & $\begin{array}{l}70 \% \mathrm{~m}+30 \% \mathrm{fs}^{3} \\
70 \% c+30 \% \mathrm{sml}\end{array}$ & $\begin{array}{l}40 \% \mathrm{~m}+60 \% \mathrm{fs} \\
40 \% c+60 \% \mathrm{sm}\end{array}$ & & \\
\hline
\end{tabular}

Ganho de peso vivo

Live weight gain

Total

$20,22 \quad 19,13$

Diário (Daily)

0,74

19,13

0,70

20,40

19,92

1,15

Ganho de altura

Height gain

Total

$1,26 \quad 2,32$

Diário (Daily)

0,07

2,32

0,09

2,31

0,09

1,96

0,09

0,86

Ganho de perímetro torácico

Heart girth gain

Total (Total)

4,57

0,17

4,88

5,48

4,98

0,18

0,56

Diário(Daily)

0,18

0,20

0,02

${ }^{1}$ Desvio-padrão da média (Standard deviation).

$2 \mathrm{~m}=$ milho; fs = farelo de soja ( $c=$ corn; $s m=$ soybean meal).

Rud et al. (2002) forneceram milho para novilhas em pastagem de azevém anual e não obtiveram resposta de ganho de peso ou de consumo total de matéria seca em relação às não-suplementadas.

Constam na Tabela 6 os valores de referência fornecidos pelo NRC (2001) para o atendimento das exigências nutricionais de fêmeas leiteiras de raças pequenas, que atingem peso maduro de $450 \mathrm{~kg} \mathrm{com}$ ganhos de peso médio diário entre 0,7 e $0,8 \mathrm{~kg} / \mathrm{dia}$.
O valor médio da pastagem consumida ( $\mathrm{kg}$ MS/dia) de $2,36 \%$ do peso vivo aproxima-se daqueles sugeridos pelo NRC (2001), especialmente para os animais com peso superior a $200 \mathrm{~kg}$, indicando que somente a pastagem poderia ter suprido suas exigências nutricionais.

Na Tabela 7, apresentam-se os valores médios da quantidade inicial e final de massa seca de forragem, os valores da leitura do disco, a taxa de crescimento da 
Tabela 5 - Valores médios do consumo de matéria seca (kg MS/dia e \% do peso vivo), de acordo com o tipo de suplementação energético-protéica

Table 5 - Mean values of dry matter intake ( $\mathrm{kg}$ DM/day and \% of body weight) according to energy-protein supplementation type

\begin{tabular}{|c|c|c|c|c|c|}
\hline \multirow[t]{2}{*}{$\begin{array}{l}\text { Item } \\
\text { Item }\end{array}$} & \multicolumn{3}{|c|}{$\begin{array}{l}\text { Suplemento } \\
\text { Supplement }\end{array}$} & \multirow[t]{2}{*}{$\begin{array}{l}\text { Média } \\
\text { Mean }\end{array}$} & \multirow[t]{2}{*}{$\begin{array}{c}\mathrm{DP}^{1} \\
\mathrm{SD}\end{array}$} \\
\hline & $\begin{array}{c}100 \% \mathrm{~m}^{2} \\
100 \% c\end{array}$ & $\begin{array}{c}70 \% \mathrm{~m}+30 \% \mathrm{fs}^{3} \\
70 \% \mathrm{c}+30 \% \mathrm{sml}\end{array}$ & $\begin{array}{l}40 \% \mathrm{~m}+60 \% \mathrm{fs} \\
40 \% \mathrm{c}+60 \% \mathrm{sm}\end{array}$ & & \\
\hline \multicolumn{6}{|c|}{ Consumo (Intake) ${ }^{1}$} \\
\hline Total & $6,72 \mathrm{a}$ & $6,75 \mathrm{a}$ & $6,82 \mathrm{a}$ & 6,76 & 0,21 \\
\hline Pasto (Pasture) & $5,29 a$ & $5,39 a$ & $5,55 \mathrm{a}$ & 5,41 & 0,08 \\
\hline \multicolumn{6}{|c|}{ Consumo $(\text { Intake })^{2}$} \\
\hline Total & $2,78 \mathrm{a}$ & $2,97 \mathrm{a}$ & $3,10 \mathrm{a}$ & 2,95 & 0,19 \\
\hline Pasto (Pasture) & $2,19 \mathrm{a}$ & $2,37 \mathrm{a}$ & $2,52 \mathrm{a}$ & 2,36 & 0,08 \\
\hline
\end{tabular}

${ }_{1}^{1}$ Consumo em kg MS/dia (Intake as $\mathrm{kg}$ DM/day).

2 Consumo em \% peso vivo (Intake as \% of body weight).

a, b: Médias seguidas por letras distintas na mesma linha diferem $(P<0,05)$ significativamente segundo $o$ teste de Tukey.

$a, b$ : Means followed by distinct letters in the same row are different $(P<.05)$ according to Tukey test.

Tabela 6 - Estimativas das exigências nutricionais de animais de raças leiteiras pequenas (GMD 0,7 a 0,8 kg/dia), conforme o peso vivo, o consumo de matéria seca (CMS) e a porcentagem de nutrientes digestíveis totais (NDT), de proteína bruta (PB), de proteína degradável no rúmen (PDR), de proteína não-degradável no rúmen (PNR), de cálcio (Ca) e de fósforo (P) (NRC, 2001)

Table 6 - Nutritional requirements estimated according to NRC (2001) for small breeds (ADG 0.7 to $0.8 \mathrm{~kg} /$ day), according to live body weight, of total dry matter intake (DMI) and percentage of total digestible nutrients (TDN), crude protein (CP), rumen degradable protein $(R D P)$, rumen undegradable protein $(R U P)$, calcium $(C a)$ and phosphorus $(P)$

\begin{tabular}{|c|c|c|c|c|c|c|c|}
\hline $\begin{array}{l}\mathrm{PV}(\mathrm{kg}) \\
B W\end{array}$ & $\begin{array}{c}\mathrm{CMS}(\mathrm{kg} / \mathrm{d})^{1} \\
D M I\end{array}$ & $\begin{array}{c}\operatorname{NDT}(\%) \\
T D N\end{array}$ & $\begin{array}{c}\mathrm{PB}(\%) \\
C P\end{array}$ & $\begin{array}{c}\operatorname{PDR}(\mathrm{kg} / \mathrm{d}) \\
R D P\end{array}$ & $\begin{array}{c}\operatorname{PNR}(\mathrm{kg} / \mathrm{d}) \\
R U P\end{array}$ & $\begin{array}{c}\mathrm{Ca}(\mathrm{g} / \mathrm{d}) \\
\mathrm{Ca}\end{array}$ & $\begin{array}{c}\mathrm{P}(\mathrm{g} / \mathrm{d}) \\
P\end{array}$ \\
\hline 150 & $4,2(2,80)$ & $65,3-67,7$ & $14,9-15,9$ & $0,42-0,44$ & $0,21-0,23$ & $28-31$ & $13-14$ \\
\hline 200 & $5,2(2,60)$ & $65,3-67,7$ & $13,4-14,2$ & $0,52-0,54$ & $0,18-0,20$ & $29-32$ & $14-15$ \\
\hline 250 & $6,2(2,48)$ & $65,3-67,7$ & $12,5-13,2$ & $0,62-0,64$ & $0,16-0,18$ & $30-32$ & $15-16$ \\
\hline
\end{tabular}

1 Valores em parênteses estão expressos como porcentagem do peso vivo.

1 Values between bracketts are expressed as percentage of body weight.

forragem, a porcentagem de material verde em relação a material morto, a carga animal, a lotação animal e a oferta de forragem em cada período experimental.

A pastagem utilizada no presente experimento apresentou bom desenvolvimento, com massa de forragem média de forragem de $2.886 \mathrm{~kg} \mathrm{MS} / \mathrm{ha}$, no momento de entrada dos animais, e $2.235 \mathrm{~kg} \mathrm{MS} / \mathrm{ha}$, no momento de saída de cada piquete.

Segundo Poppi et al. (1987), valores de quantidade de pastagem abaixo de $1.000 \mathrm{~kg} \mathrm{MS} /$ ha podem limitar o consumo, em decorrência de fatores não-nutricionais relativos à estrutura e à qualidade da forragem que dificultam a apreensão da mesma. O aumento do consumo com o incremento da massa de forragem em pastagens temperadas pode ser explicado pela maior facilidade de apreensão e ingestão da forragem (Arnold \& Dudzinsky, 1966) ou pela maior oportunidade para selecionar a dieta (Hamilton et al., 1973).
A quantidade de forragem obtida neste trabalho evitou a ocorrência de fatores não-nutricionais limitantes do consumo e, provavelmente, permitiu aos animais a seletividade. Hamilton et al. (1973) reportam que quantidades iniciais entre 2.000 e $2.500 \mathrm{~kg} \mathrm{MS} / \mathrm{ha}$, em forrageiras temperadas de porte baixo, como azevém perene (Lolium perene L.) e trevo branco (Trifolium repens $\mathrm{L}$.), otimizariam o consumo.

Os valores iniciais de massa de forragem de pastagem obtidos no trabalho encontram-se acima daqueles citados, exceto no período 3 , porém as espécies utilizadas apresentam porte mais ereto que as relatadas por Hamilton et al. (1973), entre 2.000 e $2.500 \mathrm{~kg} / \mathrm{h} a$. Newman et al. (2002) também não verificaram efeito da suplementação nitrogenada sobre o ganho de peso de novilhas em Hermathria altissima, quando a altura das plantas foi de $40 \mathrm{~cm}$, permitindo a sua seletividade. 
Tabela 7 - Valores médios por período experimental da quantidade inicial e final de massa seca da forragem (kg MS/ha), leitura do disco $(\mathrm{cm})$, taxa de crescimento da pastagem $(\mathrm{kg} \mathrm{MS} / \mathrm{ha} / \mathrm{dia})$, porcentagem de material verde, oferta de pastagem (kg MS/100 kg PV/d), carga (kg PV/ha) e lotação (UA/ha)

Table 7 - Average values by experimental period of initial and final herbage mass ( $\mathrm{kg} D M / \mathrm{ha})$, reading of disc (cm), pasture growth rate $(\mathrm{kg} \mathrm{DM} / \mathrm{ha} / \mathrm{d})$ and percentage of live material, pasture availability ( $\mathrm{kg} D \mathrm{D} / 100 \mathrm{BW} / \mathrm{d})$, stocking rate (AU/ha)

\begin{tabular}{|c|c|c|c|c|c|c|c|}
\hline & \multicolumn{7}{|c|}{ Períodos ${ }^{1}$ (Periods) } \\
\hline & 1 & 2 & 3 & 4 & 5 & 6 & Média (Mean) \\
\hline Forragem inicial (kg MS/ha) & 3297 & 2117 & 1322 & 2881 & 3937 & 3762 & 2886 \\
\hline Initial herbage mass ( $\mathrm{kg} D M / h a)$ & & & & & & & \\
\hline Forragem final (kg MS/ha) & 1686 & 1563 & 1242 & 1906 & 3082 & 3931 & 2235 \\
\hline $\begin{array}{l}\text { Final herbage mass }(\mathrm{kg} D M / \mathrm{ha}) \\
\text { Produção de pastagem }(\mathrm{kg} \mathrm{MS} / \mathrm{ha}) \\
\text { Pasture production }(\mathrm{kg} D M / \mathrm{ha})\end{array}$ & 3964 & 3446 & 3062 & 4610 & 4848 & 4675 & 4100 \\
\hline $\begin{array}{l}\text { Leitura do disco inicial }(\mathrm{cm}) \\
\text { Initial reading of disc }(\mathrm{cm})\end{array}$ & 10,3 & 9,1 & 6,3 & 7,9 & 14,1 & 10,3 & 9,7 \\
\hline $\begin{array}{l}\text { Leitura do disco final }(\mathrm{cm}) \\
\text { Final reading of disc }(\mathrm{cm})\end{array}$ & 8,5 & 5,3 & 3,4 & 7,0 & 10,1 & 10,4 & 7,4 \\
\hline $\begin{array}{l}\text { Taxa crescimento }(\mathrm{kg} \mathrm{MS} / \mathrm{ha} / \mathrm{d}) \\
\text { Growth rate }(\mathrm{kg} D M / \mathrm{ha} / \mathrm{d})\end{array}$ & 23,9 & 42,9 & 62,2 & 61,8 & 32,5 & 42,2 & 44,2 \\
\hline $\begin{array}{l}\text { Material verde }(\%) \\
\text { Live material }(\%)\end{array}$ & 62,8 & 65,6 & 80,8 & 71,5 & 82,8 & 67,2 & 71,8 \\
\hline $\begin{array}{l}\text { Oferta forragem }(\mathrm{kg} \mathrm{MS} / 100 \mathrm{~kg} \mathrm{PV} / \mathrm{d}) \\
\text { Pasture availability }(\mathrm{kg} \mathrm{DM} / 100 \mathrm{~kg} \mathrm{BW/d})\end{array}$ & 16,0 & 8,1 & 9,1 & 11,0 & 13,4 & 11,9 & 11,6 \\
\hline Carga animal* $(\mathrm{kg} \mathrm{PV} / \mathrm{ha})$ & 2500 & 2905 & 3192 & 3619 & 3950 & 4287,5 & 3409 \\
\hline Total stocking ( $\mathrm{kg} \mathrm{BW/ha)}$ & 416,8 & 484,2 & 532,0 & 603,2 & 658,3 & 714,6 & 568,2 \\
\hline Lotação * (UA/ha) & 6,3 & 7,3 & 8,0 & 9,0 & 9,9 & 10,7 & 8,5 \\
\hline Stocking rate (AU/ha) & 1,0 & 1,2 & 1,3 & 1,5 & 1,7 & 1,8 & 1,4 \\
\hline
\end{tabular}

1 o período 1 transcorreu de 18/5 a 14/6, o período 2, de 15/6 a 15/7, o período 3 , de 16/7 a 11/8, o período 4, de 12/8 a 08/9, o período 5 , de 09/9 a 06/10 e o período 6 , de 07/10 a 03/11.

1 Period 1 was from 18/5 to 14/6, period 2 from $15 / 6$ to $15 / 7$, period 3 from $16 / 7$ to $11 / 8$, period 4 from 12/8 to 8/9, period 5 from $9 / 9$ to $6 / 10$ and period 6 lasted from $7 / 10$ to $3 / 11$.

* Os valores de lotação ou da carga animal da linha superior se referem à lotação ou carga instantânea durante os períodos de ocupação, enquanto os valores da linha inferior se referem à lotação ou carga média (período de ocupação, somado ao período de repouso).

* Upper values in rows for stocking rate or total weight/area are instantaneous values during occupation periods, while lower values are averages for each experimental period (occupation + between occupation periods).

Outra característica da pastagem que indica a sua qualidade é a proporção de material verde em relação ao material morto. Segundo Hodgson (1990), os animais selecionam preferencialmente a porção verde da forragem. No presente trabalho, a porcentagem média de material verde foi de $71,7 \%$, o que confirma a boa qualidade desta pastagem.

A quantidade de pastagem ofertada foi elevada, entre 8 e $16 \mathrm{~kg} \mathrm{MS} / 100 \mathrm{~kg} \mathrm{PV} / \mathrm{dia}$. Valores entre 9 e $12 \mathrm{~kg} \mathrm{MS} / 100 \mathrm{~kg}$ PV/dia para forragens temperadas (Poppi et al., 1987) permitem o exercício da seletividade pelos animais e, normalmente, otimizam o consumo. Em pastagens temperadas, ofertas em torno de $10 \%$ do peso vivo normalmente não limitam o consumo, nem o desempenho animal (Hodgson, 1990).

O consumo e o desempenho animal apresentam aumento decrescente com o incremento da massa de forragem de pastagem, geralmente atingindo um platô quando esta alcança de 10 a $12 \%$ do peso vivo dos animais, em condições de espécies forrageiras tempe- radas de alta qualidade, como mostram trabalhos em azevém perene associado ou não ao trevo branco (Hodgson, 1990). Resultados semelhantes foram encontrados por Moraes (1992) na Depressão Central do Rio Grande do Sul, com pastagens formadas por azevém anual, trevo branco e capim pangola (Digitaria decumbens), em que o desempenho animal foi maximizado, quando a oferta variou entre 7,5 e 10\%.

Neste trabalho, a carga animal foi baixa e não se contou com animais extras para regular a oferta de pastagem. Dessa forma, trabalhou-se com lotação fixa menor que a desejável. Trabalhos com azevém anual ou azevém mais aveia, no Rio Grande do Sul, mostram ser possível utilizar cargas de 700 a $1000 \mathrm{~kg}$ $\mathrm{PV} / \mathrm{ha}$, sem comprometer o desempenho dos animais (Rocha, 1999).

A ausência de efeito global dos tratamentos sobre o desenvolvimento corporal das novilhas ainda pode ter sido influenciada pela composição química da pastagem oferecida aos animais (Tabelas 8 e 9). 
Pode-se constatar a boa qualidade da pastagem por intermédio dos teores médios de proteína bruta $(18,95 \%$ e $20,86 \%)$, FDN $(53,13 \%$ e $51,05 \%)$, respectivamente, na massa de forragem e na pastagem aparentemente consumida pelos animais, além do valor de DIVMO média $(68,27 \%)$ na pastagem aparentemente consumida. Estes valores mostram que, do ponto de vista da concentração de nutrientes, a pastagem não limitou o crescimento destes animais, que necessitavam de $65 \%$ de NDT e, pelo menos, $15 \%$ de PB (Tabela 6).

O percentual de FDN e de FDA ficou abaixo de $60 \%$ e $30 \%$, respectivamente, valores citados por Noller et al. (1996) como críticos ao consumo. Ketelaars et al. (1999) verificaram que o efeito marginal de suplementos ricos em nitrogênio sobre o consumo de pastagem diminuiu até apresentar efeito nulo para relações de N:MOD (nitrogênio: matéria orgânica digestível) de 0,01 até maiores que $0,03 \mathrm{~g} / \mathrm{g}$.
No presente estudo, as relações N:DIVMO foram maiores que 0,03 (Tabela 8).

Dessa forma, a ausência de efeitos dos suplementos sobre o desenvolvimento corporal das novilhas poderia estar relacionada à quantidade total de forragem presente em cada período experimental, à carga animal praticada, à qualidade da pastagem disponível e àquela aparentemente consumida pelos animais e que poderia satisfazer suas exigências nutricionais.

Deve-se considerar, também, que novilhas leiteiras em recria devem apresentar crescimento ótimo, e não máximo, a fim de evitar problemas decorrentes da deposição de gordura em torno dos ovários e da glândula mamária (Lucci, 1989; NRC, 2001).

$\mathrm{Na}$ Tabela 10, encontram-se as medidas iniciais e finais dos animais do experimento e os valores recomendados pela literatura para as diferentes faixas etárias.

Tabela 7 - Valores médios por período experimental da quantidade inicial e final de massa seca da forragem (kg MS/ha), leitura do disco $(\mathrm{cm})$, taxa de crescimento da pastagem $(\mathrm{kg} \mathrm{MS} / \mathrm{ha} / \mathrm{dia})$, porcentagem de material verde, oferta de pastagem (kg MS/100 kg PV/d), carga (kg PV/ha) e lotação (UA/ha)

Table 7 - Average values by experimental period of initial and final herbage mass ( $\mathrm{kg} D M / \mathrm{ha})$, disc reading (cm), pasture growth rate ( $\mathrm{kg} \mathrm{DM} / \mathrm{ha} / \mathrm{d})$, percentage of live material, pasture availability ( $\mathrm{kg} D M / 100 \mathrm{BW} / \mathrm{d})$ and stocking rate (AU/ha)

\begin{tabular}{|c|c|c|c|c|c|c|c|}
\hline & \multicolumn{6}{|c|}{ Períodos ${ }^{1}$ (Periods) } & \multirow[b]{2}{*}{ Média (Mean) } \\
\hline & 1 & 2 & 3 & 4 & 5 & 6 & \\
\hline $\begin{array}{l}\text { Forragem inicial (kg MS/ha) } \\
\text { Initial herbage mass ( } \mathrm{kg} D M / \mathrm{ha})\end{array}$ & 3297 & 2117 & 1322 & 2881 & 3937 & 3762 & 2886 \\
\hline $\begin{array}{l}\text { Forragem final }(\mathrm{kg} \mathrm{MS} / \mathrm{ha}) \\
\text { Final herbage mass }(\mathrm{kg} \mathrm{DM} / \mathrm{ha})\end{array}$ & 1686 & 1563 & 1242 & 1906 & 3082 & 3931 & 2235 \\
\hline $\begin{array}{l}\text { Produção de pastagem ( } \mathrm{kg} \mathrm{MS} / \mathrm{ha}) \\
\text { Pasture production }(\mathrm{kg} \mathrm{DM} / \mathrm{ha})\end{array}$ & 3964 & 3446 & 3062 & 4610 & 4848 & 4675 & 4100 \\
\hline $\begin{array}{l}\text { Leitura do disco inicial }(\mathrm{cm}) \\
\text { Initial reading of disc }(\mathrm{cm})\end{array}$ & 10,3 & 9,1 & 6,3 & 7,9 & 14,1 & 10,3 & 9,7 \\
\hline $\begin{array}{l}\text { Leitura do disco final }(\mathrm{cm}) \\
\text { Final reading of disc }(\mathrm{cm})\end{array}$ & 8,5 & 5,3 & 3,4 & 7,0 & 10,1 & 10,4 & 7,4 \\
\hline $\begin{array}{l}\text { Taxa crescimento }(\mathrm{kg} \mathrm{MS} / \mathrm{ha} / \mathrm{d}) \\
\text { Growth rate }(\mathrm{kg} D M / \mathrm{ha} / \mathrm{d})\end{array}$ & 23,9 & 42,9 & 62,2 & 61,8 & 32,5 & 42,2 & 44,2 \\
\hline $\begin{array}{l}\text { Material verde }(\%) \\
\text { Live material }(\%)\end{array}$ & 62,8 & 65,6 & 80,8 & 71,5 & 82,8 & 67,2 & 71,8 \\
\hline $\begin{array}{l}\text { Oferta de forragem }(\mathrm{kg} \mathrm{MS} / 100 \mathrm{~kg} \mathrm{PV} / \mathrm{d}) \\
\text { Pasture availability }(\mathrm{kg} D M / 100 \mathrm{~kg} \mathrm{BW/d})\end{array}$ & 16,0 & 8,1 & 9,1 & 11,0 & 13,4 & 11,9 & 11,6 \\
\hline Carga animal* (kg PV/ha) & 2500 & 2905 & 3192 & 3619 & 3950 & 4287,5 & 3409 \\
\hline Total stocking ( $\mathrm{kg} \mathrm{BW/ha)}$ & 416,8 & 484,2 & 532,0 & 603,2 & 658,3 & 714,6 & 568,2 \\
\hline Lotação * (UA / ha) & 6,3 & 7,3 & 8,0 & 9,0 & 9,9 & 10,7 & 8,5 \\
\hline Stocking rate $(A U / h a)$ & 1,0 & 1,2 & 1,3 & 1,5 & 1,7 & 1,8 & 1,4 \\
\hline
\end{tabular}

1 O período 1 transcorreu de 18/5 a 14/6, o período 2, de 15/6 a 15/7, o período 3, de 16/7 a 11/8, o período 4, de 12/8 a 08/9, o período 5 , de 09/9 a 06/10 e o período 6 , de 07/10 a 03/11.

${ }^{1}$ Period 1 was from 18/5 to $14 / 6$, period 2 from $15 / 6$ to $15 / 7$, period 3 from $16 / 7$ to $11 / 8$, period 4 from $12 / 8$ to $8 / 9$, period 5 from $9 / 9$ to $6 / 10$ and period 6 lasted from $7 / 10$ to $3 / 11$

* Os valores de lotação ou da carga animal da linha superior se referem à lotação ou carga instantânea durante os períodos de ocupação, enquanto os valores da linha inferior se referem à lotação ou carga média (período de ocupação, somado ao período de repouso).

* Upper values in rows for stocking rate or total weight/area are instantaneous values during occupation periods, while lower values are averages for each experimental period (occupation + between occupation periods).

\section{R. Bras. Zootec., v.34, n.1, p.175-187, 2005}


Tabela 8 - Valores médios da composição química da massa de forragem no início e no final de cada período experimental: porcentagens de matéria mineral (MM), proteína bruta (PB), fibra em detergente neutro (FDN) e fibra em detergente ácido (FDA) - valores sobre \% da matéria seca

Table 8 - Average values of chemical composition of herbage mass at the beginning and at the end of each experimental period: percentages of ash, crude protein (CP), neutral detergent fiber (NDF) and acid detergent fiber (ADF) - values as percentage of dry matter

\begin{tabular}{|c|c|c|c|c|c|c|c|}
\hline & \multicolumn{6}{|c|}{ Períodos ${ }^{1}$ (Periods) } & \multirow[b]{2}{*}{ Média (Mean) } \\
\hline & 1 & 2 & 3 & 4 & 5 & 6 & \\
\hline MM inicial (Ash - beginning) & 11,17 & 11,73 & 10,65 & 11,50 & 09,01 & 08,73 & 10,46 \\
\hline MM final (Ash - final) & 12,39 & 14,94 & 15,05 & 11,84 & 09,78 & 08,60 & 12,1 \\
\hline $\mathrm{PB}$ inicial ( $C P$ - beginning) & 20,62 & 23,58 & 18,24 & 24,33 & 15,64 & 11,30 & 18,95 \\
\hline PB final $(C P-$ final $)$ & 14,62 & 20,98 & 14,08 & 18,95 & 12,79 & 08,65 & 15,01 \\
\hline FDN inicial (NDF - beginning) & 50,17 & 52,48 & 52,45 & 48,34 & 52,56 & 62,80 & 53,13 \\
\hline FDN final $(N D F-$ final $)$ & 54,02 & 55,41 & 57,92 & 57,28 & 56,05 & 67,67 & 58,06 \\
\hline FDA inicial ( $A D F$ - beginning) & 23,07 & 24,43 & 26,03 & 22,52 & 20,98 & 26,65 & 23,95 \\
\hline FDA final $(A D F-e n d)$ & 28,41 & 31,50 & 30,69 & 24,99 & 31,42 & 34,03 & 30,17 \\
\hline
\end{tabular}

1 O período 1 transcorreu de 18/5 a 14/6, o período 2, de 15/6 a 15/7, o período 3, de 16/7 a 11/8, o período 4, de 12/8 a 08/9, o período 5 , de $09 / 9$ a $06 / 10$ e o período 6 , de $07 / 10$ a $03 / 11$.

${ }^{1}$ Period 1 was from $18 / 5$ to $14 / 6$, period 2 from $15 / 6$ to $15 / 7$, period 3 from $16 / 7$ to $11 / 8$, period 4 from $12 / 8$ to $8 / 9$, period 5 from $9 / 9$ to $6 / 10$ and period 6 lasted from $7 / 10$ to $3 / 11$

Tabela 9 - Valores médios da composição química da pastagem aparentemente consumida: percentagens de matéria mineral (MM), proteína bruta (PB), fibra em detergente neutro (FDN), fibra em detergente ácido (FDA), digestibilidade in vitro da matéria seca (DIVMS) e da matéria orgânica (DIVMO) e relação nitrogênio: DIVMO, por período experimental - valores sobre $100 \%$ da matéria seca

Table 9 - Average values of chemical composition of apparently consumed pasture: percentages of ash, crude protein (CP), neutral detergent fiber (NDF) and acid detergent fiber (ADF), in vitro dry matter digestibility (IVDMD), in vitro digestibility of organic matter (IVDOM) and nitrogen:IVDOM ratio per experimental period - values as percentage of dry matter

\begin{tabular}{lccccccc}
\hline & \multicolumn{7}{c}{ Períodos ${ }^{1}$ (Periods) } \\
\cline { 2 - 7 } & 1 & 2 & 3 & 4 & 5 & 6 & Média (Mean) \\
\hline MM (Ash) & 11,00 & 15,65 & 10,10 & 10,18 & 9,31 & 8,24 & 10,75 \\
PB (CP) & 22,47 & 25,26 & 20,50 & 24,19 & 18,85 & 13,90 & 20,86 \\
FDN $($ NDF) & 50,19 & 62,26 & 47,27 & 46,03 & 49,07 & 51,46 & 51,05 \\
FDA $(A D F)$ & 24,28 & 27,43 & 22,66 & 25,29 & 23,95 & 26,65 & 25,04 \\
DIVMO (IVDDM) & 69,87 & 61,44 & 68,77 & 70,40 & 72,72 & 73,29 & 69,41 \\
DIVMS $($ IVDOM) & 67,66 & 61,79 & 67,97 & 68,97 & 71,64 & 71,59 & 68,27 \\
N:DIVMO $($ N:IVDOM) & 0,05 & 0,07 & 0,05 & 0,05 & 0,04 & 0,03 & 0,05 \\
\hline
\end{tabular}

1 o período 1 transcorreu de 18/5 a 14/6, o período 2, de 15/6 a 15/7, o período 3 , de $16 / 7$ a 11/8, o período 4 , de 12/8 a 08/9, o período 5 , de $09 / 9$ a 06/10 e o período 6 , de $07 / 10$ a $03 / 11$.

1 Period 1 was from 18/5 to $14 / 6$, period 2 from $15 / 6$ to $15 / 7$, period 3 from $16 / 7$ to $11 / 8$, period 4 from 12/8 to 8/9, period 5 from $9 / 9$ to $6 / 10$ and period 6 lasted from $7 / 10$ to $3 / 11$.

Observa-se que existe importante defasagem entre os valores considerados ideais para esta raça, nas diferentes etapas de desenvolvimento (Heinrichs \& Hargrove, 1991), e os valores apresentados pelos animais ao início do experimento, o que sugere a ocorrência de restrição alimentar e nutricional limitando a expressão do potencial de crescimento destes animais, durante o manejo de cria e início da fase de recria, antes do início deste experimento.

Após operíodode permanência nos abrigos individuais, durante a fase de aleitamento e imediatamente posterior ao desaleitamento, os animais foram transferidos para pastagem nativa, com reduzida qualidade (época de final de verão) e menor quantidade, retardando seu crescimento. Isto enfatiza a necessidade de boas pastagens e/ou forragem conservada para manter o desenvolvimento dos animais dentro das metas estabelecidas.

$\mathrm{Na}$ Tabela 11, comparam-se os valores finais de desempenho corporal dos animais experimentais com os valores recomendados (Hoffman, 1997; Heinrichs, 1996; Pennsylvania State University, 2001).

Percebe-se que os animais atingiram os valores recomendados, à medida que se aproximaram da idade reprodutiva, ultrapassando os valores de peso 
Tabela 10 - Valores de peso vivo, perímetro torácico e altura obtidos no início do experimento (Exp) versus valores recomendados na literatura (Lit) e as diferenças entre estes (Dif)

Table 10 - Values of body weight, heart girth, and height at withers obtained at the beggining of the experiment (Exp) versus suggested values found in the literature (Lit) and the differences between them (Dif)

\begin{tabular}{|c|c|c|c|c|c|c|c|c|c|}
\hline \multirow[t]{3}{*}{$\begin{array}{l}\text { Idade (meses) } \\
\text { Age (months) }\end{array}$} & \multicolumn{3}{|c|}{$\begin{array}{l}\text { Peso vivo inicial }(\mathrm{kg}) \\
\text { Initial body weight }(\mathrm{kg})\end{array}$} & \multicolumn{3}{|c|}{$\begin{array}{r}\text { Altura }(\mathrm{cm}) \\
\text { Height }(\mathrm{cm})\end{array}$} & \multicolumn{3}{|c|}{$\begin{array}{c}\text { Perímetro torácico }(\mathrm{cm}) \\
\text { Heart girth }(\mathrm{cm})\end{array}$} \\
\hline & Exp & Lit* & Dif & Exp & Lit* & Dif & Exp & Lit* & Dif \\
\hline & Exp & Lit & Dif & Exp & Lit & Dif & Exp & Lit & Dif \\
\hline 6 & 91,4 & 127 & $-35,6$ & 109,0 & 94,0 & $+15,0$ & 150,0 & 114,3 & $+35,5$ \\
\hline 8 & 90,0 & 170 & $-80,0$ & 93,0 & 101,5 & $-8,5$ & 147,5 & 124,4 & $+23,1$ \\
\hline 10 & 148,0 & 192 & $-44,0$ & 101,0 & 103,5 & $-2,5$ & 129,0 & 129,5 & $-0,5$ \\
\hline 12 & 156,5 & 238 & $-81,5$ & 104,0 & 109,5 & $-5,5$ & 133,0 & 142,2 & $-9,2$ \\
\hline 14 & 187,0 & 254 & $-67,0$ & 111,5 & 113,0 & $-1,5$ & 142,0 & 147,3 & $-5,3$ \\
\hline 16 & 216,5 & 278 & $-61,5$ & 114,5 & 115,0 & $-0,5$ & 147,5 & 152,4 & $-4,9$ \\
\hline 18 & 236,0 & 303 & $-67,0$ & 117,0 & 117,0 & 0,0 & 150,0 & 155,0 & $-5,0$ \\
\hline
\end{tabular}

* Pennsylvania State University (2001).

Tabela 11 - Valores de peso vivo, perímetro torácico e altura na cernelha obtidos ao final do experimento (Exp) versus valores recomendados na literatura (Lit) e as diferenças entre estes (Dif)

Table 11 - Values of body weight, heart girth and height at withers obtained at the end of the experiment (Exp) versus suggested values found in the literature (Lit) and the differences between them (Dif)

\begin{tabular}{|c|c|c|c|c|c|c|c|c|c|}
\hline \multirow[t]{3}{*}{$\begin{array}{l}\text { Idade (meses) } \\
\text { Age (months) }\end{array}$} & \multicolumn{3}{|c|}{$\begin{array}{l}\text { Peso vivo final }(\mathrm{kg}) \\
\text { Final body weight }(\mathrm{kg})\end{array}$} & \multicolumn{3}{|c|}{$\begin{array}{l}\text { Altura }(\mathrm{cm}) \\
\text { Height }(\mathrm{cm})\end{array}$} & \multicolumn{3}{|c|}{$\begin{array}{c}\text { Perímetro torácico }(\mathrm{cm}) \\
\text { Heart girth }(\mathrm{cm})\end{array}$} \\
\hline & Exp & Lit* & Dif & Exp & Lit* & Dif & Exp & Lit* & Dif \\
\hline & Exp & Lit & Dif & Exp & Lit & Dif & Exp & Lit & Dif \\
\hline 12 & 211,0 & 238 & $-27,0$ & 110 & 109,5 & $+0,5$ & 143,0 & 142,2 & 0,8 \\
\hline 14 & 202,0 & 254 & $-52,0$ & 109 & 113,0 & $-4,0$ & 140,5 & 147,3 & $-6,8$ \\
\hline 16 & 250,0 & 278 & $-28,0$ & 115 & 115,0 & 0,0 & 150,0 & 152,4 & $-2,4$ \\
\hline 18 & 278,5 & 303 & $-24,5$ & 115 & 117,0 & $-2,0$ & 160,0 & 155,0 & $+5,0$ \\
\hline 20 & 340,5 & 328 & $+12,5$ & 118 & 119,0 & $-1,0$ & 169,5 & 160,0 & $+9,5$ \\
\hline 22 & 353,0 & 346 & $+7,0$ & 119 & 121,0 & $-2,0$ & 174,0 & 165,0 & $+9,0$ \\
\hline 24 & 367,0 & 378 & $-11,0$ & 121 & 124,0 & $-3,0$ & 174,0 & 170,0 & $+4,0$ \\
\hline
\end{tabular}

Pennsylvania State University (2001).

vivo, o que, em excesso, pode acarretar inconvenientes quanto à fertilidade e à produção de leite, sobretudo se a idade ao primeiro serviço não for antecipada (Lucci, 1989; NRC 2001).

Nesta condição de composição nutritiva e de oferta, a pastagem supriu as exigências das fêmeas. A carga animal também pode ter representado um fator favorável ao desempenho uniforme dos animais, visto que a baixa lotação facilitou a seleção de forragem de melhor qualidade.

Houve efeito do período experimental $(\mathrm{P}<0,05)$ sobre as características avaliadas de ganho de peso, ganho de peso diário, ganho de perímetro torácico e ganho de perímetro torácico diário (Tabela 12).

No período 4 , os animais apresentaram os maiores ganhos de peso e de perímetro torácico, em decorrência da melhor quantidade de forragem e da compo- sição da pastagem (PB 24,19\% e FDN 46,03\%). Neste período, o maior teor de proteína bruta, menor FDN e maior proporção de componentes verdes da pastagem permitiu o atendimento das necessidades dos animais, de acordo com o NRC (2001) (Tabela 6). Ressalva-se que os valores de incremento de perímetro torácico obtidos no quinto período podem conter erros, uma vez que apresentam valor negativo.

O baixo desempenho animal observado nos períodos 1 e 2 (de $18 / 05$ a $14 / 06$ e de $15 / 06$ a 15/07, respectivamente) reflete a menor quantidade de material verde e, no período 3 (de 16/07 a 11/08), coincide com queda no desenvolvimento da pastagem, graças aos dias de frio intenso, poucas horas de luminosidade (Tabela 13), com baixa taxa de crescimento da pastagem de azevém e ainda com a agravante de uma infestação de fungos do gênero Fusarium na aveia, o 
Tabela12 - Valores médios de ganho de peso por período experimental e diário, ganho de altura na cernelha por período experimental e diário das novilhas em pastejo e suplementadas

Table 12 - Average values of body weight gain, height at withers gain at each experimental period and daily for grazing heifers supplementation

\begin{tabular}{|c|c|c|c|c|}
\hline $\begin{array}{l}\text { Períodos } \\
\text { Periods }\end{array}$ & $\begin{array}{c}\text { Ganho de peso } \\
(\mathrm{kg}) \\
\text { Weight gain }\end{array}$ & $\begin{array}{c}\text { Ganho de peso diário } \\
(\mathrm{kg} / \mathrm{d}) \\
\text { Daily weight gain }\end{array}$ & $\begin{array}{c}\text { Ganho de altura } \\
(\mathrm{cm}) \\
\text { Height gain }\end{array}$ & $\begin{array}{c}\text { Ganho de altura diário } \\
(\mathrm{cm} / \mathrm{d}) \\
\text { Daily height gain }\end{array}$ \\
\hline 1 & $16,63 b$ & $0,616 b$ & $1,50 \mathrm{a}$ & $0,12 \mathrm{ab}$ \\
\hline 2 & $16,53 \mathrm{~b}$ & $0,5511 b$ & $0,87 \mathrm{ab}$ & $0,03 \mathrm{ab}$ \\
\hline 3 & $17,47 \mathrm{~b}$ & $0,672 b$ & $1,70 \mathrm{ab}$ & $0,07 \mathrm{ab}$ \\
\hline 4 & $26,53 \mathrm{a}$ & $0,983 \mathrm{a}$ & $4,99 \mathrm{a}$ & $0,18 \mathrm{a}$ \\
\hline 5 & $20,90 \mathrm{ab}$ & $0,774 \mathrm{ab}$ & $-1,91 b$ & $-0,06 b$ \\
\hline 6 & $21,43 \mathrm{ab}$ & $0,794 \mathrm{ab}$ & $4,66 \mathrm{a}$ & $0,17 \mathrm{a}$ \\
\hline
\end{tabular}

1 O período 1 transcorreu de 18/5 a 14/6, o período 2, de 15/6 a 15/7, o período 3, de 16/7 a 11/8, o período 4, de 12/8 a 08/9, o período 5 , de $09 / 9$ a $06 / 10$ e o período 6 , de $07 / 10$ a $03 / 11$.

${ }_{1}^{1}$ Period 1 was from 18/5 to 14/6, period 2 from $15 / 6$ to 15/7, period 3 from 16/7 to 11/8, period 4 from 12/8 to 8/9, period 5 from $9 / 9$ to $6 / 10$ and period 6 lasted from $7 / 10$ to $3 / 11$.

$a, b=$ Médias seguidas por letras distintas em mesma coluna, diferem $(P<0,05)$ pelo teste Tukey.

$a, b=$ Means followed by distinct letters in the same column are different $(P<.05)$ according to Tukey test.

Tabela 13 - Valores médios e normais a cada mês, respectivamente para temperatura média $\left(\mathrm{TME},{ }^{\circ} \mathrm{C}\right)$, temperatura mínima (TMIN, $\left.{ }^{\circ} \mathrm{C}\right)$, temperatura máxima (TMAX, ${ }^{\circ} \mathrm{C}$ ), precipitação pluviométrica (PREC, mm), umidade relativa do ar (UR, \%), número de dias de chuva (DCHU), número de dias de geada (DGE) e insolação (INS, horas)

Table 13 - Monthly and normal average values for mean temperature (MET, $\left.{ }^{\circ} \mathrm{C}\right)$, minimal temperature (MINT, $\left.{ }^{\circ} \mathrm{C}\right)$, maximal temperature $\left(M X T,{ }^{\circ} \mathrm{C}\right)$, rainfall $(R F, m m)$, relative umidity $(R U, \%)$, number of rainy days $(N R D)$, number of frost days (NFD) and hours of sun shinning (HSS)

\begin{tabular}{|c|c|c|c|c|c|c|c|c|}
\hline \multicolumn{9}{|c|}{ Atributos climáticos (Climatic attributes) } \\
\hline Mês & TME & TMIN & TMAX & PREC & UR & DCHU & DGE & INS \\
\hline Month & $M E T$ & MINT & $M X T$ & $R F$ & $R U$ & $N R D$ & $N F D$ & $H S S$ \\
\hline Maio & $15,3^{*}$ & 12,2 & 20,0 & 241,2 & 86,5 & 13 & 1 & 177,9 \\
\hline May & 15,2 & 10,6 & 20,8 & 83,9 & 83,3 & 8,5 & 2,8 & 182,9 \\
\hline Junho & 14,8 & 11,8 & 19,4 & 199,2 & 87,6 & 10 & 3 & 96,5 \\
\hline June & 12,6 & 8,4 & 17,9 & 92,8 & 83,6 & 9,7 & 6 & 150,5 \\
\hline Julho & 10,7 & 7,3 & 15,4 & 144,8 & 80,9 & 8 & 9 & 18,0 \\
\hline July & 12,6 & 8,6 & 17,6 & 132,8 & 85,4 & 10,7 & 5,1 & 150,0 \\
\hline Agosto & 12,4 & 8,0 & 18,2 & 133,3 & 80,7 & 7 & 10 & 218,2 \\
\hline August & 13,5 & 9,4 & 18,3 & 137,6 & 83,6 & 10,7 & 4,1 & 158,5 \\
\hline Setembro & 14,0 & 9,8 & 18,7 & 171,0 & 84,6 & 8 & 3 & 189,3 \\
\hline September & 15,1 & 11,2 & 19,4 & 137,0 & 82,2 & 10,9 & 20 & 153,0 \\
\hline Outubro & 17,7 & 15,0 & 21,3 & 118,4 & 84,7 & 17 & 0 & 160,0 \\
\hline October & 17,6 & 13,2 & 22,1 & 94,6 & 79,0 & 9,6 & 0,6 & 205,9 \\
\hline
\end{tabular}

* valores mensais relativos ao ano de 2000 e na linha de baixo os valores normais.

* Monthly values on 2000 and on the lower row normal values.

que resultou em extensas áreas de pastagem recusada pelos animais.

Durante o período 3 , foi observado menor consumo de pastagem pelos animais em relação ao último período experimental (Tabela 14). A proporção de material verde:seco e a ocorrência de Fusarium, que dificultaram a apreensão da forragem e, por conseguinte, reduziram o consumo, constituem um fator preponderante do efeito do período experimental sobre o desempenho animal.

\section{Conclusões}

Diferentes tipos de suplementação energéticoprotéica não modificaram o desenvolvimento corporal de novilhas Jersey mantidas em pastagem de aveia preta (Avena strigosa, Schreb) e azevém anual (Lolium multiflorum, Lam), durante o ciclo de desenvolvimento da pastagem, graças à quantidade de massa de forragem e ao seu valor nutricional. 
Tabela 14 - Valores médios de consumo de matéria seca (MS) total e de pastagem

Table 14 - Mean values for total and pasture dry matter intake (DMI)

\begin{tabular}{lcccc}
\hline Item & \multicolumn{2}{c}{$\begin{array}{c}\text { Períodos } \\
\text { Item }\end{array}$} & \multirow{2}{*}{$\begin{array}{c}\text { Média } \\
\text { Mean }\end{array}$} & $\mathrm{CV}(\%)$ \\
\cline { 2 - 3 } $\begin{array}{l}\text { Consumo (kg MS/dia) } \\
\text { Intake (kg DM/day) }\end{array}$ & 3 & 6 & & \\
\hline Total & & & & \\
$\begin{array}{l}\text { Pastagem } \\
\text { Pasture }\end{array}$ & $5,61 \mathrm{~b}$ & $7,91 \mathrm{a}$ & 6,83 & 16,23 \\
Consumo (\% PV) & & $6,41 \mathrm{a}$ & 5,47 & 18,71 \\
$\begin{array}{l}\text { Intake (\% BW) } \\
\text { Total }\end{array}$ & & & & \\
$\begin{array}{l}\text { Pastagem } \\
\text { Pasture }\end{array}$ & $2,81 \mathrm{a}$ & $3,09 \mathrm{a}$ & 2,95 & 14,26 \\
& $2,21 \mathrm{a}$ & $2,51 \mathrm{a}$ & 2,36 & 17,25 \\
& & & & \\
\hline
\end{tabular}

1 coeficiente de variação (coefficient of variation).

a, b: Médias seguidas por letras distintas na mesma linha diferem $(P<0,05)$ significativamente segundo o teste $F$.

$a, b$ : Means followed by distinct letters in the same row are different $(P<.05)$ according to $F$ test.

\section{Literatura Citada}

ARNOLD, G.W.; DUDZINSKI, M.L. The behavior response controlling the food intake of grazing sheep. In: INTERNATIONAL GRASSLAND CONGRESS, 10., 1966, Helsinki. Proceedings... Helsinki: International Grassland Society, 1966. p.367-370.

ASSOCIATION OF OFFICIAL ANALITICAL CHEMISTAOAC. Offcial methods of analysis. 12.ed. Washington, D.C.: $1975.1094 p$.

BITTENCOURT, D.; PEGORARO, L.M.C.;GOMES, J.F. et al. Sistemas de pecuária de leite: uma visão na região de clima temperado. Pelotas: Embrapa Clima Temperado, 2000. $195 \mathrm{p}$.

BOIN,C.; TEDESCHI, L.O. Sistemas intensivos de produção de carne bovina: II. Crescimento e acabado. In: PEIXOTO, A.M. (Ed.). Produção de novilhos de corte. Piracicaba: Fundação de Estudos Agrários Luiz de Queiroz, 1996. p.205-225.

CAMPOS, O.F.; LIZIEIRE, R.S. Estratégias para obtenção de fêmeas de reposição em rebanhos leiteiros. In: PLANEJAMENTO DA EXPLORAÇÃO LEITEIRA. SIMPÓSIO SOBRE PRODUÇÃO ANIMAL, 10., 1998, Piracicaba. Anais... Piracicaba: Fundação de Estudos Agrários Luiz de Queiroz, 1998. p.215-256.

GARDNER, A.L. Técnicas de pesquisa em pastagens e aplicabilidade de resultados em sistemas de produção Brasília: IICA/EMBRAPA-CNPGL, 1986. 197p.

GOERING, H.K.; Van SOEST, P.J. Forage fiber analysis. Washington, D.C.: Agriculture Research Service US Department of Agriculture, 1970. (Agricultural Handbook, 379)

HAMILTON, B.A.; HUTCHINSON, K.J.; ANNIS, P.C. et al. Relationship between the diet selected by grazing sheep and the herbage on offer. Australian Journal of Agriculture Research, v.24, p.271-277, 1973.
HEINRICHS, A.J.; HARGROVE, G.L. Standards of weight and height for Guernsey and Jersey heifers. Journal of Dairy Science, v.74, p.1684-1689, 1991.

HEINRICHS, A.J. Nutrition and management of replacement cattle. Animal Feed Science and Technology, v.59, n.1-3, p.155-166, 1996.

HODGSON, J. Grazing management: science into practice. Inglaterra: Longman Handbooks in Agriculture, 1990. 203p.

HOFFMAN, P.C. Manejo de um sistema de criação de novilhas à base de pastagem. Dez fatores-chave para o sucesso. In: Novos enfoques na produção e reprodução de bovinos. Botucatu: CONAPEC, 2000. p.38-44.

HORN, G.W.; CRAVEY, M.D.; McCOLLUM, F.T. et al. Influence of high starch vs high fiber energy supplements on steers grazing summer native rangeland. Journal of Animal Science, v.73, n.1, p.45-54, 1995.

IBGE. Instituto Brasileiro de Geografia e Estatística. Disponível em: 〈http://www.ibge.com.br> Acesso em: 04-05-2001.

JACQUES, A.V.A.; SAIBRO, J.C.; LOBATO, J.F.P. et al. Sistemas de produção de forragens para a Depressão Central, RS. In: FEDERACITE, IV, CADEIAS FORRAGEIRAS REGIONAIS. Porto Alegre: FEDERACITE, 1995. p.13-28.

. Potencialidades das pastagens do Rio Grande do Sul visando à intensificação da pecuária. In: LOBATO, J.F.P. (Ed.). Produção de bovinos de corte. Porto Alegre: PUCRS, 1999. p.67-76.

KETELAARS, J.J.M.H.; KASSCHIETER, G.A.; KANE, M. Effects of intake of supplementing low quality roughage with protein-rich feeds. In: INTERNATIONAL GRASSLAND CONGRESS, 11., 1999, Canada. Proceedings.... Canada: International Grassland Society, 1999. Cd-ROM, Seção 2.

LUCCI, C. Bovinos leiteiros jovens. Nutrição, manejo, doenças. São Paulo: Nobel/Edusp, 1989. 371p.

MOORE, J.E. Crop quality storage and utilization. In: HOVELAND, C.S. (Ed.). Madison: American Society of Agronomy, 1980. p.61-91.

MORAES, A. Produtividade animal e dinâmica de uma pastagem de pangola (Digitaria decumbens Stent), azevém (Lolium multiflorum, L.) e trevo branco (Trifolium repens, L.) submetida a diferentes pressões de pastejo. Porto Alegre: Universidade Federal do Rio Grande do Sul, 1992. Tese (Doutorado em Zootecnia) - Universidade Federal do Rio Grande do Sul, 1992.

NATIONAL RESEARCH COUNCIL - NRC. Nutrient requirements of dairy cattle. 7.ed. Washington, D.C.: National Academic Press, 2001. 381p.

NEWMAN, Y.C.; SOLLENBERGER, L.E.; KUNKLE, W.E. et al. Canopy height and nitrogen effects on performance of heifers grazing Limpograss. Agronomy Journal, v.94, p.1375-1380, 2002.

NOLLER, C.H.; NASCIMENTO Jr., D.; QUEIROZ, D.S. In: SIMPÓSIO SOBRE MANEJO DA PASTAGEM, 13., 1996. Piracicaba. Anais... Piracicaba: Fundação de Estudos Agrários Luiz de Queiroz, 1996. p.319-352.

PIAGGIO, L. Parâmetros determinantes do consumo e seletividade de novilhos em pastejo em campo nativo melhorado. Porto Alegre: Universidade Federal do Rio Grande do Sul, 1994. Tese (Doutorado em Zootecniaa) Universidade Federal do Rio Grande do Sul, 1994.

PENNSYLVANIA STATE UNIVERSITY, 2001. Extension Circular 385 - Management of Dairy Heifers. Disponível em <www. teamdairy/special> Acesso em 17.07.2001. 
POPPI, D.P.; HUGHES, T.P.; L'HUILLIER, P.J. Intake of pasture by grazings ruminants. In: NICOL, A.M. (Ed.). Feeding livestock on pasture. New Zealand: New Zealand Society of Animal Production, 1987. p.55-63. (Occasional publications, 10)

REIS, R.A.; RODRIGUES, L.R.; PEREIRA, J.R. A suplementação como estratégia de manejo da pastagem. In: PEIXOTO, A. (Ed.). Produção de bovinos a pasto. Piracicaba: Fundação de Estudos Agrários Luiz de Queiroz, 1996. p.123-150.

ROCHA, M.G. Suplementação a campo de bovinos de corte. In: LOBATO, J.F. (Ed.). Produção de bovinos de corte. Porto Alegre: PUCRS, 1999. p.77-96.

RUD, B.J.; HANSON, K.C.; TUCKER, W.B. Effect of supplementing corn or hay to beef cattle consuming annual ryegrass (Lolium multiflorum) on performance and nutrient utilization. Journal of Applied Animal Research, v.21, p.35-48, 2002.
STATISTICAL ANALYSES SYSTEM - SAS. Version for WIN-Release 6.11. Cary: 1989.

TILLEY, J.M.; TERRY, R.A. A two-stage technique for the "in vitro" digestion of forage crops. Journal of British Grassland Society, v.18, n.2, p.104-111, 1963.

Recebido em: 07/03/03

Aceito em: 25/08/04 